\title{
Delayed headache after COVID-19 vaccination: a red flag for vaccine induced cerebral venous thrombosis
}

David García-Azorín”, Thien Phu Do², Andreas R. Gantenbein ${ }^{3,4}$, Jakob Møller Hansen, Marcio Nattan P. Souza ${ }^{6}$, Mark Obermann ${ }^{7,8}$, Heiko Pohl ${ }^{9}$, Christoph J. Schankin ${ }^{10}$, Henrik Winther Schytz ${ }^{5}$, Alexandra Sinclair ${ }^{11,12}$, Guus G. Schoonman ${ }^{13+}$ and Espen Saxhaug Kristoffersen ${ }^{14,15^{*+}}$ (B)

\begin{abstract}
Background: Headache is a frequent symptom following COVID-19 immunization with a typical onset within days post-vaccination. Cases of cerebral venous thrombosis (CVT) have been reported in adenovirus vector-based COVID19 vaccine recipients.

Findings: We reviewed all vaccine related CVT published cases by April 30, 2021. We assessed demographic, clinical variables and the interval between the vaccination and onset of headache. We assessed whether the presence of headache was associated with higher probability of death or intracranial hemorrhage.

We identified 77 cases of CVT after COVID-19 vaccination. Patients' age was below 60 years in 74/77 (95.8\%) cases and 61/68 (89.7\%) were women. Headache was described in 38/77 (49.4\%) cases, and in 35/38 (92.1\%) was associated with other symptoms. Multiple organ thrombosis was reported in 19/77 (24.7\%) cases, intracranial hemorrhage in 33/77 (42.9\%) cases and 19/77 (24.7\%) patients died. The median time between vaccination and CVT-related headache onset was 8 (interquartile range 7.0-9.7) days. The presence of headache was associated with a higher odd of intracranial hemorrhage (OR 7.4; 95\% Cl: 2.7-20.8, $p<0.001$ ), but not with death (OR: 0.51, 95\% Cl: 0.18-1.47, $p=0.213$ ).

Conclusion: Delayed onset of headache following an adenovirus vector-based COVID-19 vaccine is associated with development of CVT. Patients with new-onset headache, 1 week after vaccination with an adenovirus vector-based vaccine, should receive a thorough clinical evaluation and CVT must be ruled out.
\end{abstract}

Keywords: Headache disorders, Secondary; sinus thrombosis, Vaccine-induced immune thrombotic thrombocytopenia, Cerebrovascular disorders; Stroke

\footnotetext{
* Correspondence: e.s.kristoffersen@medisin.uio.no

${ }^{\dagger}$ Guus G. Schoonman and Espen Saxhaug Kristoffersen shared last

authorship.

${ }^{14}$ Department of Neurology, Akershus University Hospital, Lørenskog, Norway

${ }^{15}$ Department of General Practice, HELSAM, University of Oslo, Oslo, Norway

Full list of author information is available at the end of the article
}

(C) The Author(s). 2021 Open Access This article is licensed under a Creative Commons Attribution 4.0 International License, which permits use, sharing, adaptation, distribution and reproduction in any medium or format, as long as you give appropriate credit to the original author(s) and the source, provide a link to the Creative Commons licence, and indicate if changes were made. The images or other third party material in this article are included in the article's Creative Commons licence, unless indicated otherwise in a credit line to the material. If material is not included in the article's Creative Commons licence and your intended use is not permitted by statutory regulation or exceeds the permitted use, you will need to obtain permission directly from the copyright holder. To view a copy of this licence, visit http://creativecommons.org/licenses/by/4.0/ The Creative Commons Public Domain Dedication waiver (http://creativecommons.org/publicdomain/zero/1.0/) applies to the data made available in this article, unless otherwise stated in a credit line to the data. 


\section{Introduction}

Headache is within the most frequent adverse effects following coronavirus disease 2019 (COVID-19) immunization. It is reported by approximately half of the vaccine recipients, both in clinical trials and realworld data $[1,2]$. Headache typically presents within the first $72 \mathrm{~h}$ post-vaccination and may be associated with additional symptoms, such as fatigue, fever, myalgia, arthralgia, or diarrhea $[1,2]$.

Several cases of cerebral venous thrombosis (CVT) have been reported in non-replicant adenovirus vectorbased COVID-19 vaccine recipients (Oxford-AstraZeneca ChAdOx1-S and Johnson \& Johnson (J\&J) Janssen Ad26.COV2S) [3-7]. The association was based on the presence of thrombocytopenia [3-8], anti-platelet factor 4 antibodies [6, 7], and multiple organ thrombosis (vaccine-induced immune thrombotic thrombocytopenia (VITT) ) [3-8]. There was a higher mortality rate [3-8] than in other CVT series reported in the literature and an increased standardized morbidity ratio (SMR) in patients aged between 30 and 49 [3]. SMR is also known as observed-to-expected analysis, which analyses the ratio between the observed number of cases in the population over the number of cases that would be expected based on the baseline incidence according to databases and prior studies $[9,10]$.

Headache is the most frequent symptom in CVT, and it may occur isolated or accompanied by other symptoms [9-11]. As in other secondary headache disorders, CVT may be recognized by the presence of red flags $[11,12]$. Herein we highlight a potential novel red flag based on the available scientific data that may help clinicians to properly identify cases of CVT following non-replicant adenovirus vector-based COVID-19 vaccines.

\section{Methods}

This is an observational study with case-control design. The study population were vaccinated with nonreplicant adenovirus vector-based vaccines. The case definition was CVT following COVID-19 non-replicant adenovirus vector-based vaccines. We screened PubMed for all published cases and case series between March 01 and April 30, 2021, and assessed specific reports from the United States Centers for Disease Control and Prevention and the European Medicines Agency providing patient-level data. The search term is available in the supplementary appendix. We assessed and extracted the following variables, which are presented as descriptive statistics: age, sex, use of contraceptives or hormonereplacement therapy, presence of headache, presence of additional symptoms, the interval between the vaccination and the first symptom, intracranial hemorrhage, and death. We compared the time elapsed between vaccination and the first clinical onset in patients with and without headache. As control group, we reviewed the United States Vaccine Adverse Event Reporting System (VAERS) [2] reports under the symptom "headache" following COVID-19 vaccination up to April 30, 2021, assessing the number of days between the immunization and the headache onset. In the statistical analysis, we assessed whether the presence of headache in patients with CVT was associated with higher probability of death or with higher probability of intracranial hemorrhage by univariate logistic regression, presented as odds ratio (OR) and 95\% confidence interval (CI). The statistical signification threshold was 0.05 and statistical tests were two-tailed. No statistical power calculation was conducted prior to the study. Statistical analysis was done with SPSS version 26.0.

\section{Results}

We identified 77 cases of CVT included in eight publications (supplementary appendix). Patients' age was available in 71 cases, and was below 40 in $46.5 \%$, below 60 in $95.8 \%$ and between 60 and 69 years in $4.2 \%$ cases. The majority of cases $61 / 68$ (89.7\%) were women. Five (5.2\%) patients used contraceptives and one $(1.3 \%)$ received estrogen therapy.

The median time between the vaccination and the first symptom was 8 days (inter-quartile range (IQR) $7-12$, range $1-19, n=70)$. The presence of headache was described in 38/77 cases (49.4\%). In 35/38 patients $(92.1 \%)$, it was associated with other systemic or neurological symptoms. The CVT-related clinical symptoms started earlier in patients with headache (median 8, IQR 7-9.7, range 2-15) than in patients without headache (median 10, IQR 7-12.2, range 1$19),(P=0.037$, Mann-Whitney test $)$. Figure 1 shows the days elapsed between vaccination and headache onset. Intracranial hemorrhage was present in 33/77 (42.9\%) cases, multiple location thrombosis was reported in 19/77 (24.7\%) cases, and 19/77 (24.7\%) died. In patients with CVT, the presence of headache was associated with the presence of intracranial hemorrhage (odds ratio (OR) 7.45; 95\% confidence interval (CI): $2.67-20.80, P<0.001)$, but not with a higher odd of death (OR: 0.51, 95\% CI: 0.18-1.47, $P=0.213$ ).

\section{Discussion}

Although headache is a common symptom after vaccination, it typically presents and resolves within the same day or a few days later $[1,2]$. CVT, and other thrombotic complications in adenovirus-based vaccine recipients share a unique feature, the delayed presentation. In most of the reported cases symptoms started 1 week after immunization. Headache was not described in detail in most cases, but in the few it was, it was reported as 


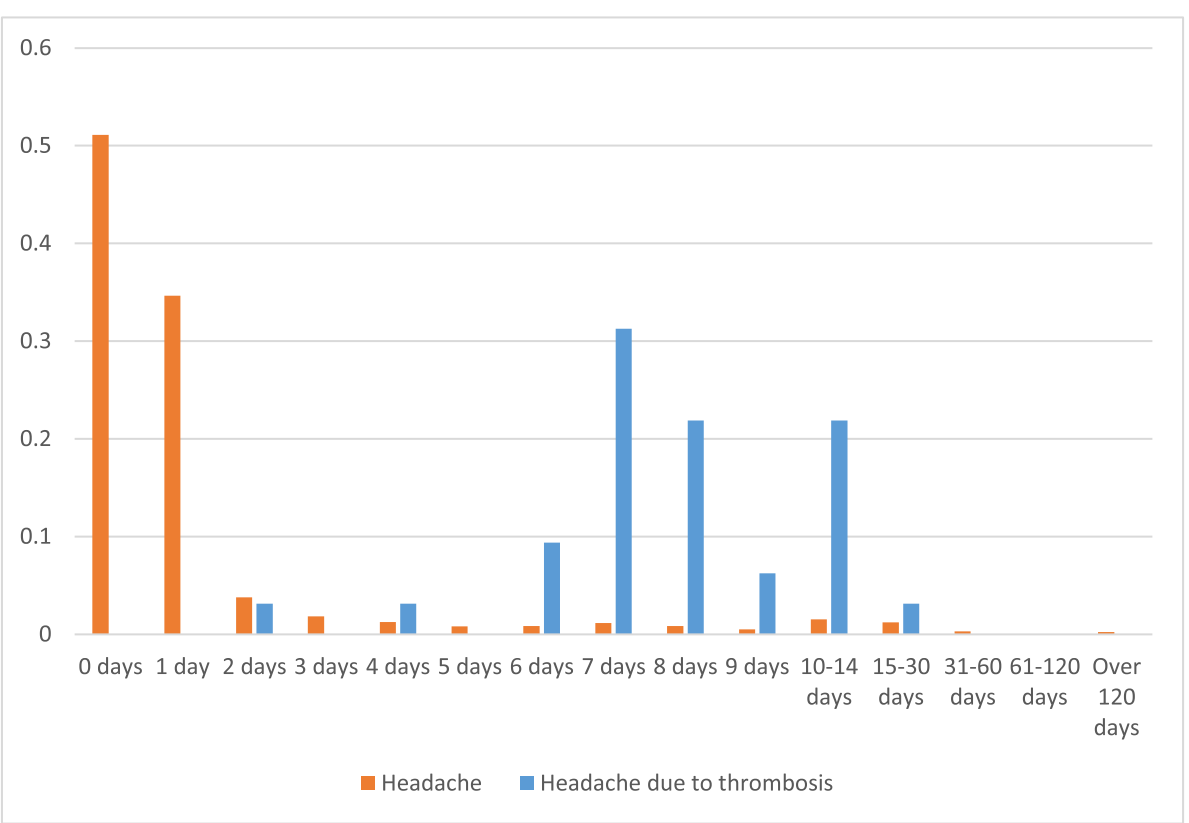

Fig. 1 Temporal distribution of vaccine-related headache in the general population and vaccine-related cerebral venous sinus thrombosis headache. Orange bars represent the proportion of patients that present headache during each day after vaccination according to VAERS data ${ }^{2}$. Blue bars represent the proportion of patients with headache attributed to vaccine-related cerebral venous sinus thrombosis

severe, progressive and treatment-resistant, all of them well-known red flags [ 12].

Diagnostic delay is common in CVT [9]. Prompt treatment likely improves the clinical outcome, and therefore, every physician must be aware of the potential risk of vaccine related thrombotic complications. Given this knowledge and the possibility of vaccine-related CVT, patients with new-onset headache, 1 week after immunization, should receive a thorough clinical evaluation and be closely monitored. Non-contrast.

computed tomography (CT) may detect indirect findings of CVT, including hyperdense vein or sinus (cord sign), venous infarcts, brain oedema and intracranial hemorrhages; however, the optimal imaging test in case of suspicion are contrast brain CT with CT venogram, magnetic resonance imaging (MRI) with contrast and/or venogram, showing a filling defect in a venous sinus (empty delta sign) $[10,13]$.

The pathophysiology of thrombosis with thrombocytopenia syndrome has been recently discussed $[7,14,15]$. The role of anti-platelet factor- 4 antibodies seem causative, inducing platelet activation, aggregation, and thrombosis, leading to a severe platelet consumption and thrombocytopenia. According to the existing evidence, an interim guideline published by the World Health Organization (WHO) states that the treatment should include the treatment of the immune-mediated phenomenon and adequate anticoagulation according to the existing evidence [14]. For the first, intravenous immunoglobulins seem to be the preferred option, while as anticoagulants, non-heparin-based anticoagulants must be used, while heparin-based anticoagulants and platelet infusion should be avoided [14].

\section{Conclusion}

To conclude, delayed onset of headache following an adenovirus vector-based COVID-19 vaccine is associated with CVT. Patients with new-onset headache, 1 week after vaccination with an adenovirus vector-based vaccine, should receive a thorough clinical evaluation and CVT must be considered in the diagnostic work-up.

\section{Supplementary Information}

The online version contains supplementary material available at https://doi. org/10.1186/s10194-021-01324-5.

\section{Additional file 1.}

\section{Acknowledgements}

Not applicable.

\section{Authors' contributions}

All authors contributed in the interpretation of data for the work, critical revision of the work for important intellectual content and all authors gave their final approval of the work to be published. All authors had full access to the full data used in the manuscript and accept responsibility to submit it for publication.

\section{Funding}

No funding sources were involved in the writing of this manuscript or the decision to submit it for publication. 


\section{Availability of data and materials}

Datasheets are fully available to other researchers upon request to the corresponding author.

\section{Declarations}

\section{Ethics approval and consent to participate}

The study was conducted in accordance with Helsinki Declaration as revised in 2013. According to local IRB no ethical approval or informed patient consent was necessary because no new individually collected patient data were used in this study. For this type of study formal consent is not required.

\section{Consent for publication}

Not applicable.

\section{Competing interests}

David García-Azorín received scientific support and received honoraria from the Brain Health Unit of the World Health Organization as scientific advisor for the COVID-19 Global Forum.

Thien Phu Do reports no conflicts of interest.

Andreas R. Gantenbein reports no conflicts of interest.

Jakob Møller Hansen reports no conflicts of interest.

Marcio Nattan Souza received speaker fees from Novartis, TEVA, Lilly, Allergan, Sanofi, Libbs and Lundbeck.

Mark Obermann received scientific support, travel support and/or honoraria from Biogen Idec, Novartis, Sanofi/Genzyme, Pfizer, Teva, Lilly, Schwarz and Heel. He received research grants from Allergan, Electrocore, Heel, and the German Ministry for Education and Research (BMBF).

Heiko Pohl was funded by the Werner Dessauer Stiftung and received speaker fees from TEVA Pharmaceuticals and honoraria from Eli Lilly. Christoph J. Schankin received scientific support, travel support and/or honoraria from Novartis, Eli Lilly, TEVA Pharmaceuticals, Allergan, Almirall, Amgen, MindMed, Grünenthal. He received research grants from German Migraine and Headache Society, Eye on Vision Foundation, and Baasch Medicus Foundation. He is part-time employee at Zynnon.

Henrik Winther Schytz has received honoraria from Novartis, TEVA, Lilly and has received a research grant from Novartis.

Alexandra Sinclair has received speaker fees and Honoraria from Novartis and Allergan.

Guus Schoonman reports no conflict of interest.

Espen Saxhaug Kristoffersen reports no conflicts of interest.

\section{Author details}

${ }^{1}$ Headache Unit, Department of Neurology, Hospital Clínico Universitario de Valladolid, Valladolid, Spain. ${ }^{2}$ The Danish Headache Center, Department of Neurology, Rigshospitalet-Glostrup, Faculty of Health Sciences, University of Copenhagen, Glostrup, Denmark. ${ }^{3}$ Department of Neurology and Neurorehabilitation, ZURZACH Care, Bad Zurzach, Switzerland. ${ }^{4}$ Department of Neurology, University Hospital Zurich, Zürich, Switzerland. ${ }^{5}$ Danish Headache Center, Rigshospitalet-Glostrup, Faculty of Health Sciences, University of Copenhagen, Glostrup, Denmark. 'Department of Neurology, Hospital das Clínicas, University of São Paulo, São Paulo, Brazil. ${ }^{7}$ Department of Neurology, Hospital Weser-Egge, Höxter, Germany. ${ }^{8}$ Department of Neurology, University of Duisburg-Essen, Essen, Germany. 'Department of Neurology, University Hospital Zurich, Zurich, Switzerland. ${ }^{10}$ Department of Neurology, Inselspital, Bern University Hospital, University of Bern, Bern, Switzerland. ${ }^{11}$ Metabolic Neurology, Institute of Metabolism and Systems Research, College of Medical and Dental Sciences, University of Birmingham, Birmingham B15 2TT, UK. ${ }^{12}$ Department of Neurology, University Hospitals Birmingham NHS Foundation Trust, Birmingham B15 2TH, UK. ${ }^{13}$ Department of Neurology, Elisabeth-TweeSteden Hospital, Tilburg, The Netherlands. ${ }^{14}$ Department of Neurology, Akershus University Hospital, Lørenskog, Norway. ${ }^{15}$ Department of General Practice, HELSAM, University of Oslo, Oslo, Norway.

\section{Received: 16 August 2021 Accepted: 6 September 2021} Published online: 17 September 2021

\section{References}

1. Zhu FC, Li YH, Guan XH, Hou LH, Wang WJ, Li JX, Wu SP, Wang BS, Wang Z, Wang $L$, Jia SY, Jiang HD, Wang $L$, Jiang T, Hu Y, Gou JB, Xu SB, Xu JJ, Wang
XW, Wang W, Chen W (2020) Safety, tolerability, and immunogenicity of a recombinant adenovirus type- 5 vectored COVID-19 vaccine: a doseescalation, open-label, non-randomised, first-in-human trial. Lancet 395(10240):1845-1854. https://doi.org/10.1016/S0140-6736(20)31208-3

2. Vaccine Adverse Event Reporting System (VAERS). VAERS Data Sets. Available on: https://vaers.hhs.gov/data.html Accessed on May 10, 2021

3. European Medicines Agency. Signal assessment report on embolic and thrombotic events (SMQ) with COVID-19 Vaccine (ChAdOx1-S [recombinant]) - Vaxzevria (previously COVID-19 Vaccine AstraZeneca) (Other viral vaccines). Published on 08 April 2021. Available on: https:// www.ema.europa.eu/en/documents/prac-recommendation/signal-a ssessment-report-embolic-thrombotic-events-smq-covid-19-vaccine-cha dox1-s-recombinant_en.pdf

4. Krzywicka K, Heldner MR, Sánchez van Kammen M, van Haaps T, Hiltunen S, Silvis SM, Levi M, Kremer Hovinga JA, Jood K, Lindgren E, Tatlisumak T, Putaala J, Aguiar de Sousa D, Middeldorp S, Arnold M, Coutinho JM, Ferro JM (2021) Post-SARS-CoV-2-vaccination cerebral venous sinus thrombosis: an analysis of cases notified to the European medicines agency. Eur J Neurol (Epub ahead of print). https://doi.org/10.1111/ene.15029

5. Schulz JB, Berlit P, Diener HC, Gerloff C, Greinacher A, Klein C, Petzold GC, Piccininni M, Poli S, Röhrig R, Steinmetz H, Thiele T, Kurth T, the German Society of Neurology SARS-CoV-2 Vaccination Study Group, Alonso A, Bartsch T, Baumsteiger C, Bode F, Cangür H, Daffertshofer M, Dafotakis M, Dieterich M, Fabian F, Fousse M, Godau J, Grond M, Günther A, Gutschalk A, Hagemann G, Hartmann C, Hilker-Roggendorf R, Höglinger G, Ikenberg B, Ismail FS, Jesse S, Kallmünzer B, Kern R, Klietz M, Knauß S, Knier B, Limmroth V, Mengel A, Meyne J, Morgenthaler M, Müller M, Nagel S, Niels RD, Onur OA, Pelz J, Plenge J, Poli S, Roth C, Röther J, Saß C, Schönenberger S, Schubert R, Simon O, Agaplesion IS, Sperfeld A, Spreer A, Steinbrecher A, Steiner J, Stetefeld H, Trendelenburg G, Vatankhah NB, Wahl CM, Wartenberg K, Witt K, Wittstock M, Wolf B, Wolf J, Zimmermann J (2021) COVID-19 vaccine-associated cerebral venous thrombosis in Germany. Ann Neurol (Epub ahead of print). https://doi.org/10.1002/ana.26172

6. See I, Su JR, Lale A, Woo EJ, Guh AY, Shimabukuro TT, Streiff MB, Rao AK, Wheeler AP, Beavers SF, Durbin AP, Edwards K, Miller E, Harrington TA, MbaJonas A, Nair N, Nguyen DT, Talaat KR, Urrutia VC, Walker SC, Creech CB, Clark TA, DeStefano F, Broder KR (2021) US case reports of cerebral venous sinus thrombosis with thrombocytopenia after Ad26.COV2.S vaccination, march 2 to April 21, 2021. JAMA 325(24):2448-2456. https://doi.org/10.1001/ jama.2021.7517

7. Greinacher A, Thiele T, Warkentin TE, Weisser K, Kyrle PA, Eichinger S (2021) Thrombotic thrombocytopenia after ChAdOx1 nCov-19 vaccination. N Engl J Med 84(22):2092-2101. https://doi.org/10.1056/NEJMoa2104840

8. Pottegård A, Lund LC, Karlstad $\varnothing$ et al (2021) Arterial events, venous thromboembolism, thrombocytopenia, and bleeding after vaccination with Oxford-AstraZeneca ChAdOx1-S in Denmark and Norway: population based cohort study. BMJ 373:n1114

9. Kristoffersen ES, Harper CE, Vetvik KG, Zarnovicky S, Hansen JM, Faiz KW (2020) Incidence and mortality of cerebral venous thrombosis in a Norwegian population. Stroke 51(10):3023-3029. https://doi.org/10.1161/ STROKEAHA.120.030800

10. Silvis SM, de Sousa DA, Ferro JM, Coutinho JM (2017) Cerebral venous thrombosis. Nat Rev Neurol 13(9):555-565. https://doi.org/10.1038/ nrneurol.2017.104

11. García-Azorín D, Monje MHG, González-García N, Guerrero ÁL, Porta-Etessam $J$ (2020) Presence of red flags in patients with cerebral venous sinus thrombosis admitted to the emergency department because of headache: a STROBE compliant cohort-study. Medicine (Baltimore) 99(29):e20900. https://doi.org/10.1097/MD.0000000000020900

12. Do TP, Remmers A, Schytz HW, Schankin C, Nelson SE, Obermann M, Hansen JM, Sinclair AJ, Gantenbein AR, Schoonman GG (2019) Red and orange flags for secondary headaches in clinical practice: SNNOOP10 list. Neurology 92(3):134-144. https://doi.org/10.1212/WNL.0000000000006697

13. FACME multidisciplinary working group on the management of cerebral venous sinus thrombosis associated with COVID-19 vaccination. Diagnostic and treatment recommendations from the FACME ad-hoc expert working group on the management of cerebral venous sinus thrombosis associated with COVID-19 vaccination. Neurologia (Engl Ed) Jul-Aug 2021 36(6):451461. Doi: https://doi.org/10.1016/j.nrleng.2021.05.001

14. World Health Organization. Guidance document for clinical case management of thrombosis with thrombocytopenia syndrome (TTS) 
following coronavirus disease (COVID-19) vaccination. Interim guidance 1 July 2021. Available on: https://apps.who.int/iris/bitstream/handle/10665/342 999/WHO-2019-nCoV-TTS-2021.1-eng.pdf

15. Schultz NH, Sørvoll IH, Michelsen AE, Munthe LA, Lund-Johansen F, Ahlen MT, Wiedmann M, Aamodt AH, Skattør TH, Tjønnfjord GE, Holme PA (2021) Thrombosis and thrombocytopenia after ChAdOx1 nCoV-19 vaccination. N Engl J Med 384(22):2124-2130. https://doi.org/10.1056/NEJMoa2104882

\section{Publisher's Note}

Springer Nature remains neutral with regard to jurisdictional claims in published maps and institutional affiliations.

Ready to submit your research? Choose BMC and benefit from:

- fast, convenient online submission

- thorough peer review by experienced researchers in your field

- rapid publication on acceptance

- support for research data, including large and complex data types

- gold Open Access which fosters wider collaboration and increased citations

- maximum visibility for your research: over $100 \mathrm{M}$ website views per year

At BMC, research is always in progress.

Learn more biomedcentral.com/submissions 